\title{
Topical Report to Morgantown Energy Technology Center for the Interfacial Coatings for Ceramic-Matrix Composites
}

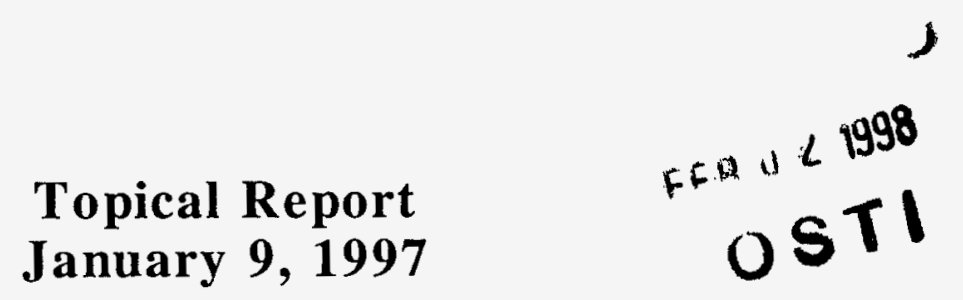

\section{3}

Work Performed Under Contract No.: DE-AC21-95MC32085

For

U.S. Department of Energy Office of Fossil Energy Federal Energy Technology Center Morgantown Site P.O. Box 880

Morgantown, West Virginia 26507-0880

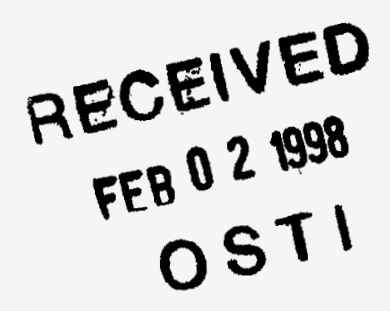

By

Northwestern University's Industrial

Research Laboratory

1801 Maple Avenue

Evanston, Illinois 60201-3140 


\section{Disclaimer}

This report was prepared as an account of work sponsored by an agency of the United States Grovernment. Neither the United States Government nor any agency thereof, nor any of their employees, makes any warranty, express or implied, or assumes any legal liability or responsibility for the accuracy, completeness, or usefulness of any information, apparatus, product, or process disclosed, or represents that its use would not infringe privately owned rights. Reference herein to any specific commercial product, process, or service by trade name, trademark, manufacturer, or otherwise does not necessarily constitute or imply its endorsement, recommendation, or favoring by the United States Government or any agency thereof. The views and opinions of authors expressed herein do not necessarily state or reflect those of the United States Government or any agency thereof. 


\section{TABLE OF CONTENTS}

\section{ACKOWLDGEMENTS}

EXECUTIVE SUMMARY............................................................................................................................

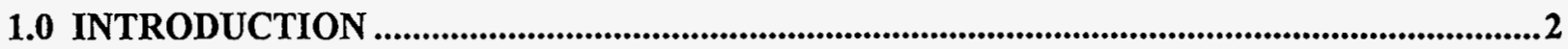

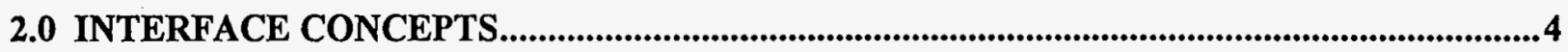

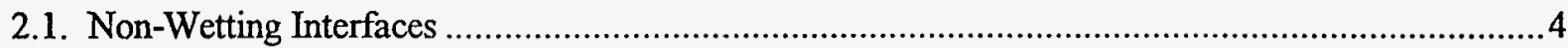

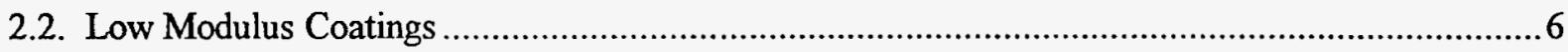

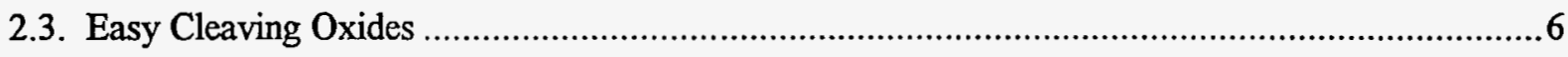

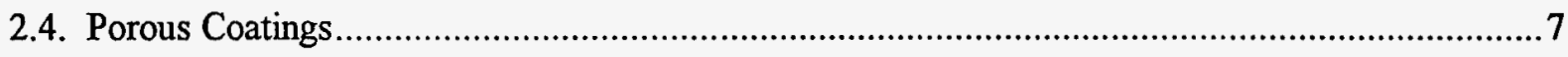

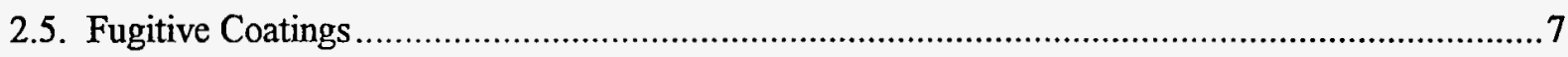

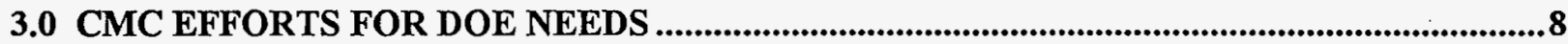

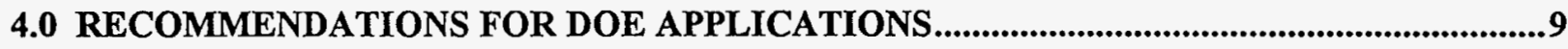

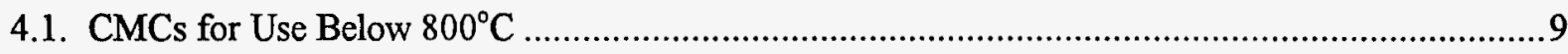

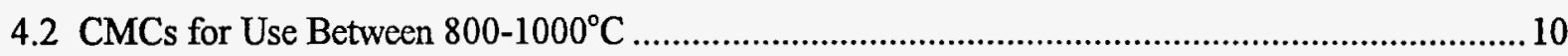

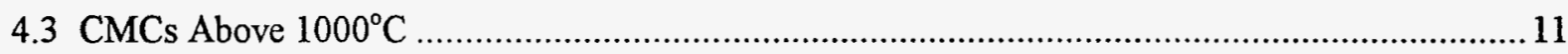

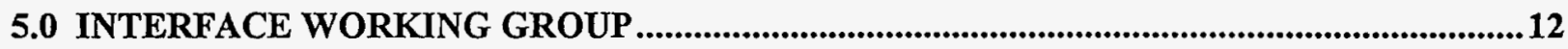

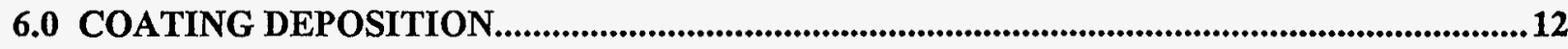

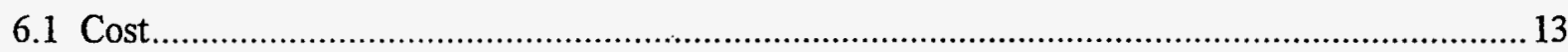

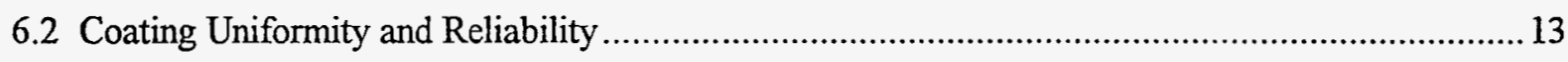

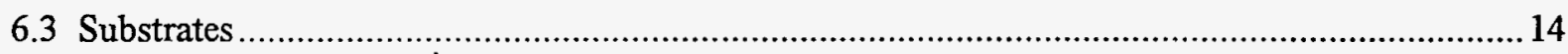

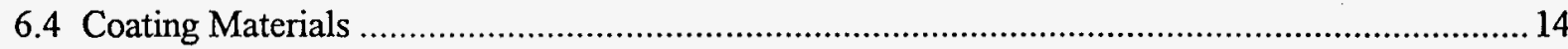

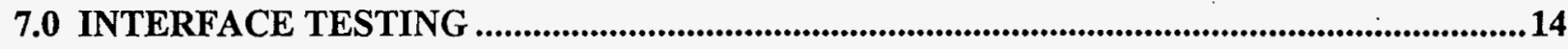

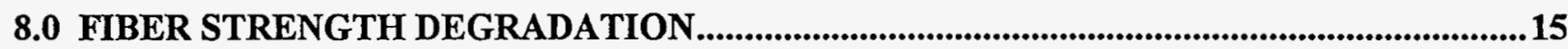

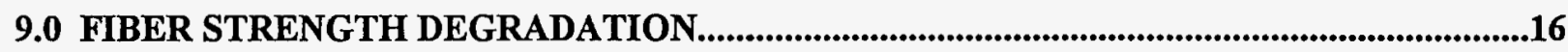

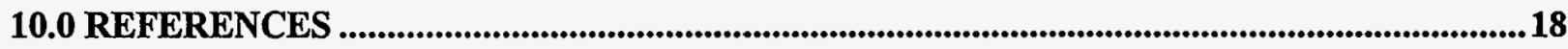

\section{LIST OF TABLES}

Table 1. Interface Concepts Under Evaluation. 4 


\section{ACKNOWLEDGEMENTS}

I am grateful to several of my colleagues in the $\mathrm{CMC}$ community for sharing information that was useful in the preparation of this report. I would like to thank Mr. Daniel E. Boss for many helpful discussions and editorial comments. I would also like to thank Mr. Ted McMahon, DOE/METC, for his support for this activity. This work was performed under DOE Contract \#DE-AC21-95MC32085.

Krishan K. Chawla - New Mexico Mining \& Technology, Socorro, NM.

Craig R. Folsom - Wright Laboratory, Wright Patterson AFB, OH.

Richard W. Goettler - Babcock \& Wilcox, Lynchburg, VA.

Paul S. Gray - DuPont Lanxide Corp.,

Randall S. Hay - Wright Laboratory, Wright Patterson AFB, OH.

John R. Hellman - Pennsylvania State University, PA.

Martha H. Jaskowiak - NASA Lewis Research Center, Cleveland, OH.

Rick A. Lowden - Oak Ridge National Laboratory, Oak Ridge, TN.

Krishan Luthra - GE Corporate R\&D, Schenectady, NY

Gregory N. Morscher - NASA Lewis Research Center, Cleveland, OH.

Subbu Shanmugham- Oak Ridge National Laboratory, Oak Ridge, TN.

David P. Stinton - Oak Ridge National Laboratory, Oak Ridge, TN. 


\section{EXECUTIVE SUMMARY}

This report summarizes the task conducted to examine various activities on interface development for ceramic-matrix composites (CMCs) intended for high-temperature applications. While several articles have been published on the subject of CMC interfaces, the purpose of this report is to describe the various ongoing efforts on interface concepts, material selection, and issues related to processing methods employed for developing interface coatings.

Much of the earlier work on CMC interfaces concluded that both $\mathrm{C}$ and $\mathrm{BN}$ coatings are susceptible to oxidation at relatively low temperatures and hence may not be useful for most CMC applications. However, recent work sheds a more positive outlook for BN. Tensile tests performed on Nicalon ${ }^{\mathrm{TM}}$ fiber reinforced composites with highly crystalline and stoichiometric $\mathrm{BN}$ fiber coatings show the oxidative stability to be much higher (above $1000^{\circ} \mathrm{C}$ ). Despite these encouraging results, most researchers remain skeptical about the long term prospects for BN coatings.

The most exciting and new development in the field is the discovery of monazite as a potential interface material for mullite- and alumina-based composites. Monazite offers two critical properties to the CMC system; a weakly bonded layer due to its non-wetting behavior and chemical compatibility with both alumina and mullite up to very high temperatures $\left(>1600^{\circ} \mathrm{C}\right)$. Other interesting concepts with intensive material development efforts are also being pursued and a brief discussion of these are given in the main text.

While demonstration of new interface concepts seems to be the primary objective in most studies, difficulties in processing of interface coatings and designing reliable test methods for determining interface properties have actually retarded the progress. Some of the concepts appear to be simple in nature but require sophisticated processing schemes to develop the coatings. Multilayered coatings with each layer serving specific function are also being proposed. Recent studies also show that significant degradation in fiber strength (30-50\%) can result from merely applying the interface coating. These factors have compounded the complexity of interface tailoring in CMCs leading to a need for specific solution for a specific CMC system. 


\subsection{INTRODUCTION}

It is well recognized that the presence of an interphase layer between the fiber and matrix in ceramic-matrix composites (CMCs) is crucial in providing the necessary toughness for the composite. The interphase layer acts as a mechanical fuse by deflecting cracks, initiated from the matrix, that impinge on the fiber. The deflected cracks propogate along the fiber axis resulting in a fiber pull-out behavior which provides the damage tolerance for the composite. In order for this mechanism to be wholly functional, careful design of the interface is necessary such that both chemical as well as mechanical requirements are satisfied over the entire range of temperatures and environmental conditions.

He and Hutchinson provided the first micro-mechanical model that defined the fracture energy requirements for crack deflection to occur at the interface [1]. The model proposes that the ratio of the fracture energy of the interface to that of the fiber be less than or equal to 0.25 . For most fiber materials (e.g., alumina, $\mathrm{SiC}$ ), this requirement limits the interface strength to be less than 20 $\mathrm{MPa}$. The functionality of carbon interfacial coatings in SiC-SiC and other glass-ceramic composites is positive testimony to the model with the fracture strength of carbon being less than $10 \mathrm{MPa}$. Since the discovery of carbon interfacial coatings for CMCs, much of the research in this area is now focused on the development of oxidatively stable interface coatings. In fact, the lack of a functional interface coating that is oxidatively stable over a wide range of temperatures is the key barrier in the deployment of CMCs suited for many applications in the DOE, DoD, NASA, and commercial sectors. The first viable replacement for carbon was hexagonal BN, which is a logical progression since it is structurally similar to graphite. Early work on BN showed that it may be susceptible to oxidation at temperatures as low as $800^{\circ} \mathrm{C}$, or even $600^{\circ} \mathrm{C}$ in moist environments. But, Brennan's recent work shows that BN coatings, if developed appropriately, may survive above $1100^{\circ} \mathrm{C}$ in oxidizing environments [2]. If this is true, much of the DOE needs may be fulfilled except for fusion applications where neither BN nor $\mathrm{C}$ is desirable [3]. Despite the encouraging results on BN, most researchers remain skeptical and await further results. 
The Department of Defense's primary interest for CMCs are in turbine engine applications where the service temperatures are greater than $1200^{\circ} \mathrm{C}$. This imposes strict demands on fiber as well as interphase materials. Another DoD driver for CMCs are the need for low observable (LO) materials where the temperature and load requirements are far less severe than those in turbine engines. Nicalon ${ }^{\mathrm{TM}}$-reinforced Blackglas ${ }^{\mathrm{TM}}$ composites are being evaluated for the $\mathrm{LO}$ applications through the LC ${ }^{3}$ DARPA consortium. In their Phase II program, the consortium has identified a need for interface coatings for Blackglas ${ }^{\mathrm{TM}}$ composites with cost as an important criterion in the development. However, much of the DoD-sponsored work is focused on developing oxidatively stable interface coatings intended for service temperatures in excess of $1200^{\circ} \mathrm{C}$. In the following section, a general description of the current activities, processing issues, and interface testing methods are discussed.

Various exploratory efforts are underway in many laboratories around the world with the US taking the primary lead in developing conceptual ideas as well as in identifying appropriate coating materials. Clearly, the challenge has been two-fold. First, to develop interface concepts that are mechanically suitable while satisfying the thermal, chemical, and environmental requirements for the $\mathrm{CMC}$ system, and second, to develop appropriate processing approaches to deposit the coatings on appropriate substrates for testing the concept reliably. It is now being realized, while innovative and exciting interface concepts can be designed, carrying it through and developing appropriate processing methods is a tedious and a difficult task. Furthermore, until recently, there has been little or no effort in characterization of interface coatings in trying to understand the subtle effects of varying chemistries at the interface on its properties [4].

In this report, we first offer a brief description of the various promising concepts that are currently being evaluated. This will be followed by a description of the Department of Energy-related activities and finally, some thoughts on processing issues, interface testing, and effects of processing on fiber strength. Proceedings from a recently convened meeting on high temperature CMCs can be obtained for detailed technical information related to development of oxidationresistant interface coatings [5]. 


\subsection{INTERFACE CONCEPTS}

Table I provides a summary of the ongoing interface work. Some of the information was gathered from conversations with researchers in government, industry, and academic institutions who are actively pursuing $\mathrm{CMC}$ interface studies. While most researchers were able to share the results of their work freely, few of them could not share due to the proprietary nature of their work. The discussion below gives a general description of the various interface concepts:

Table 1. Interface Concepts Under Evaluation

\begin{tabular}{|c|c|c|c|c|c|}
\hline $\mathbf{L a b} / \mathbf{P O C}$ & Concept & $\begin{array}{c}\text { Coating } \\
\text { Material } \\
\text { (environment") }\end{array}$ & $\begin{array}{c}\text { CMC } \\
\text { Fiber/Matrix }\end{array}$ & $\begin{array}{l}\text { Coating } \\
\text { Process }\end{array}$ & Comments \\
\hline $\begin{array}{l}\text { Rockwell Intl./ } \\
\text { P.E. D. } \\
\text { Morgan }\end{array}$ & $\begin{array}{l}\text { High interfacial } \\
\text { energy }\end{array}$ & $\mathrm{LaPO}_{4}(\mathrm{~b}, \mathrm{C})$ & $\begin{array}{l}\text { Mullite/Mullite \& } \\
\text { Alumina/ Alumina }\end{array}$ & $\begin{array}{l}\text { Sol-gel, } \\
\text { CVD }\end{array}$ & $\begin{array}{l}\text { Push-out and crack deflection } \\
\text { observed }\end{array}$ \\
\hline $\begin{array}{l}\text { ORNL/ } \\
\text { D.P. Stinton }\end{array}$ & Low modulus & mullite $(\mathrm{b}, \mathrm{A})$ & $\mathrm{SiC} / \mathrm{SiC}$ & Sol-gel & $\begin{array}{l}1000^{\circ} \mathrm{C}, 200 \mathrm{~h}, \text { good strength } \& \\
\text { toughness; work in progress }\end{array}$ \\
\hline $\begin{array}{l}\text { WPAFB/ } \\
\text { T. Mah }\end{array}$ & Fugitive & N/A $(b, C)$ & mullite/mullite & CVD-C & $\begin{array}{l}\text { Graceful failure for composite } \\
\text { but concerns with load transfer; } \\
\text { work in progress }\end{array}$ \\
\hline $\begin{array}{l}\text { NASA/ } \\
\text { M. Jaskowiak }\end{array}$ & Porous coating & zirconia $(b, N)$ & $\mathrm{SiC} / \mathrm{SiC}$ & Sol-gel & $\begin{array}{l}\text { Interfacial shear strength } \\
\tau=120 \mathrm{mpa}\end{array}$ \\
\hline $\begin{array}{l}\text { Northwestern- } \\
\text { ASU/ } \\
\text { S. Sambasivan } \\
\end{array}$ & $\begin{array}{l}\text { Easy cleaving } \\
\text { oxide }\end{array}$ & $\begin{array}{l}\mathrm{KCa}_{2} \mathrm{Nb}_{3} \mathrm{O}_{10} \\
(\mathrm{~b}, ?)\end{array}$ & alumina/alumina & Sol-gel & $\begin{array}{l}\text { Highly anisotropic fracture } \\
\text { behavior observed on bulk } \\
\text { specimens }\end{array}$ \\
\hline $\begin{array}{l}\text { WPAFB/ } \\
\text { M.L. Cinibulk }\end{array}$ & $\begin{array}{l}\text { Easy cleaving } \\
\text { oxide }\end{array}$ & $\mathrm{CaAl}_{12} \mathrm{O}_{19}(\mathrm{~b}, ?)$ & alumina/alumina & Sol-gel & $\begin{array}{l}\text { Fracture surface showed basal } \\
\text { cleavage }\end{array}$ \\
\hline $\begin{array}{l}\text { ORNL/ } \\
\text { R. Lowden }\end{array}$ & $\begin{array}{l}\text { Multilayered } \\
\text { coatings }\end{array}$ & $\begin{array}{l}\mathrm{SiC} / \mathrm{C} / \mathrm{SiC} / \mathrm{C} \\
(\mathrm{r}, \mathrm{A})\end{array}$ & $\mathrm{SiC} / \mathrm{SiC}$ & CVD & Work under progress \\
\hline $\begin{array}{l}\text { United } \\
\text { Technologies/ } \\
\text { J. Brennan } \\
\end{array}$ & Dual coatings & $\mathrm{BN} / \mathrm{SiC}(\mathrm{r}, \mathrm{A})$ & Nicalon/BAS & CVD & $\begin{array}{l}\text { Good composite properties } \\
@ 1100^{\circ} \mathrm{C} \text {, air, 500h }\end{array}$ \\
\hline $\begin{array}{l}\text { U of Illinois/ } \\
\text { W. Kriven }\end{array}$ & $\begin{array}{l}\text { Phase } \\
\text { transformation }\end{array}$ & $\mathrm{MgSiO}_{3}(\mathrm{~b}, ?)$ & $\begin{array}{l}\mathrm{SiC} / \mathrm{SiC}, \\
\text { alumina/alumina }\end{array}$ & $\begin{array}{l}\text { Laser } \\
\text { ablation }\end{array}$ & Debonding observed \\
\hline
\end{tabular}

\footnotetext{
- Environtal stability above $1000^{\circ} \mathrm{C} ; \mathrm{o}=$ oxidizing, $\mathrm{r}=$ reducing, $\mathrm{b}=$ both; $\mathrm{A}=$ acidic, $\mathrm{B}=$ basic, $\mathrm{C}=$ both, $\mathrm{N}=$ neutral, ? = not known
} 


\subsection{Non-Wetting Interfaces}

This is perhaps the most recent and promising concept, which was proposed by Morgan and Marshall (Rockwell International) with monazite (lanthanum phosphate) as the coating material [6]. While the functionality of monazite as a fiber coating is still under study, it is speculated that monazite provides a non-wetting interface between the fiber and coating, (high interfacial energy) which apparently imparts a relatively low interfacial strength necessary for debonding and sliding. Monazite is a refractory material (m.p. $2140^{\circ} \mathrm{C}$ ) and phase compatible with both mullite and alumina up to very high temperatures. Preliminary results obtained from push-out tests on monazite-coated sapphire fibers in alumina matrices look promising. The coating has also been tested for its compatibility with both mullite and alumina up to $1600^{\circ} \mathrm{C}$ for $100 \mathrm{~h}$.

Under a new DARPA program, Rockwell International has teamed up with 3M and Stanford Research Institute (SRI) to form the Mullite-Matrix Composite Consortium for developing CMC with monazite interfaces designed for high temperature Air Force applications. The current emphasis on this program is the development of an economical method to deposit monazite uniformly and continuously on Nextel 720 fibers. Several Laboratories are actively developing monazite coatings on fiber tows in a continuous manner. The coating methods include sol-gel, solution, slurry, and Chemical Vapor Deposition (CVD). Under the Continuous Fiber Ceramic Composite (CFCC) Program, Babcock \& Wilcox are actively involved in developing monazite coatings on Nextel 720 and 610 tows by various solution techniques. In all cases, the critical issue appears to be the stoichiometry of lanthanum to phosphorous in the deposited coating. A slight excess of lanthanum appears to form lanthanum aluminate through a solid state reaction with the fiber. This apparently results in the degradation of the fiber strength and interface properties. Likewise, an excess of phosphorus results in the formation of aluminum phosphate which also may affect the fiber strength adversely. Therefore, the current focus is in development of appropriate solution chemistries that will offer the optimum stoichiometry as well as uniform coatings. The subject of monazite coatings was given increased attention during the recent meeting of the Annual Ceramic Society ('96) through a dedicated symposium on monazite. 


\subsection{Low Modulus Coatings}

Kerans has postulated that both carbon and $\mathrm{BN}$ offer a high degree of compliance which may be necessary for interface debonding and sliding[7]. Stinton and Coworkers have recently proposed mullite as a low modulus coating material for Nicalon/SiC composites. They are developing a trilayer coating consisting of carbon/mullite/carbon wherein the first carbon layer (20-50nm thick) was deposited by CVD to protect the fiber and the outer carbon layer ( $50 \mathrm{~nm}$ thick) was deposited to protect the coating from halide attack during matrix formation by CVD [8]. Stressstrain data obtained on composites before and after oxidation $\left(1000^{\circ} \mathrm{C}, 200 \mathrm{~h}\right)$ showed graceful failure in both cases with slight degradation in composite strength after oxidation. While this is an encouraging sign, further work is necessary to document the interface behavior in these composites and to test the long term reliability issues.

\subsection{Easy Cleaving Oxides}

Easy-Cleaving oxides are highly anisotropic compounds that possess easy cleavage planes similar to that in carbon and BN that have been proven as functional interfaces. The first candidate in the oxide family that was tested was mica-based fluorophologopites which are aluminosilicates with potassium ions residing in the "weak" interlayer region [9]. These materials reacted extensively with the fiber and matrix such that their use was limited to low temperatures. Since then, several layered oxides have emerged that show promise for high temperature use. Among them, the family of $\beta$ aluminas and magnetoplumbites of several compositions are currently being examined $[10,11]$. The alkali stabilized $\beta$ aluminas are attractive but suffer from incongruent vaporization of alkali at elevated temperatures (above $1000^{\circ} \mathrm{C}$ ). However, the magnetoplumbite structures are thermally more stable being stabilized by alkaline earth and rare earth cations. The most recent and perhaps the most encouraging result for magnetoplumbites was recently reported by Cinibulk where crystallographically oriented coatings of hibonite $\left(\mathrm{CaAl}_{12} \mathrm{O}_{19}\right)$ were deposited on sapphire fibers [12]. A TEM section of the coated fiber in alumina matrix showed cracks forming parallel to the basal planes of the hibonite. While this was encouraging, no push out for the fiber was observed in these model composites. 
Sambasivan and Petuskey have proposed a new family of layered oxides based on a layered perovskite structure with wide range of compositions such that compatible members from the family can be matched with fiber and matrix materials [13]. Based on preliminary indentation studies on bulk specimens, these materials show highly anisotropic fracture behavior and appear to be well suited for CMC interfaces. Vickers indents placed within single grains of potassium calcium niobate $\left(\mathrm{KCa}_{2} \mathrm{Nb}_{3} \mathrm{O}_{10}\right)$ show extensive cracking in the basal direction with little or no apparent crack initiated in the normal direction. Development of coatings of potassium calcium niobate on saphikon monofilaments for subsequent crack deflection tests are in progress. While $\mathrm{KCa}_{2} \mathrm{Nb}_{3} \mathrm{O}_{10}$ melts at approximately $1465^{\circ} \mathrm{C}$, other members in the layered perovskite family with much higher melting points have been identified. Some of the these candidates will also be examined during the course of the program.

\subsection{Porous Coatings}

This concept is relatively simple in that significant porosity induced into a suitable material may lower the toughness to the desired value such that morphologically and chemically stable porous

coatings may be another suitable way to design an interface. Several researchers are pursuing this approach with various materials including zirconia [14], Si-O-C [15], and $\mathrm{SiC}$ [16]. A potential concern with this approach is the tortuous crack path during debonding which may lead to increased frictional sliding. Of course, this will depend on the pore morphology and the pore distribution within the coating layer. The other concern is the sintering of the porous coating during exposure to elevated temperatures. However, with regards to DOE applications, this may not be a severe problem due to the relatively lower application temperatures. However, if the pore structure is open to the atmosphere, corrosive species can penetrate through the pores and attack the fiber causing strength degradation.

\subsection{Fugitive Coatings}

This concept epitomizes the need for a weak interface by designing one with a physical gap at the interface. Although this may be well suited for obtaining impressive debonding properties, concerns for efficient load transfer between the fiber and matrix have been raised. Mah and 
coworkers at Wright Labs are conducting an elaborate study to examine mullite-mullite composites with carbon as the fugitive coating and have reported fairly encouraging results [17]. Whether this concept will be suitable for SiC-based composites where oxidation of Nicalon fibers can occur relatively easily remain to be seen.

\subsection{CMC EFFORTS FOR DOE NEEDS}

Most of the DOE-sponsored work is focused on development of Si-based CMCs. SiC and $\mathrm{Si}_{3} \mathrm{~N}_{4}$ have low CTEs $\left(\sim 5 \mathrm{E}-06 /{ }^{\circ} \mathrm{K}\right)$, relatively high thermal conductivites, and high strengths that provide high thermal shock resistance. Under the CFCC program, except for the oxide-oxide CMC development at B\&W, the rest of the CFCC teams are developing SiC-based CMCs. DOE is also funding the development of CFCC hot-gas filters for fossil fuel power generation applications. For this application, oxide/oxide systems produced by B\&W, DuPont Lanxide Composites, and Techniweave/Westinghouse are being developed[18]. Therefore, bulk of the interface work in DOE programs is geared toward development of a functional interface coating for SiC-based systems. Much of the earlier work on interfaces under the CFCC program dealt with the development of $\mathrm{C}$ and $\mathrm{BN}$ coatings. The attention has now shifted toward the development of multilayered interface coatings. Brennan and coworkers have demonstrated that a dual layer consisting of $\mathrm{BN} / \mathrm{SiC}$ works fairly well for Nicalon/ BAS glass-ceramic composites [2]. $\mathrm{SiC}$ provides chemical protection to $\mathrm{BN}$ from the atmosphere as well as from diffusion of oxygen through the matrix while BN functions as a weak interphase. This concept has now been extended further in the development of several alternating layers of $\mathrm{Py}-\mathrm{C} / \mathrm{SiC}, \mathrm{BN} / \mathrm{SiC}$, BN/alumina, and others. The multilayer design allows for the crack deflection to occur along any one of the weak interlayers. The weak interphases are interleaved between layers of either an oxidation resistant material such as alumina or materials that form a protective silica layer such as SiC. While significant progress is being made in the development of these multilayer coatings, it is still too early to assess their viability from a technical as well as an economic standpoint.

Among other interface design approaches under study, recent findings of Naslain [19] suggest that it may be beneficial to design a stronger interface between the fiber and coating such that the fiber is always protected from atmospheric oxidation. The debonding apparently occurs through 
extensive and distributed microcracking within the coating layer over relatively short distances. The strong bond between the fiber and the coating is achieved through a proprietary pretreatment of the Nicalon fibers prior to the application of fiber coatings.

\subsection{RECOMMENDATIONS FOR DOE APPLICATIONS}

For CMC applications in non-oxidizing environments, $\mathrm{PyC}$ or $\mathrm{BN}$ coatings should serve adequately for all temperature regimes with upper limits being set only by the fiber properties at elevated temperatures. Based on the current state of development on oxidatively stable interface coatings, it is probably fair to state that there is no universal interface treatment that will function in oxidizing and corrosive environments over the entire temperature regime of interest. The need for CMCs span over several key DOE applications such as turbine engine components, heat exchangers, hot gas filters, and others where the service conditions are quite different for each application. Furthermore, for each of those applications, both the temperature and the environment may vary significantly depending on the specific power generation system. Acidic environments induced by a specific coal type, for example, may be quite inert to a $\mathrm{BN} / \mathrm{SiC}$ interface coating. However, a basic environment may severely degrade the coating even if it is exposed to similar conditions of oxygen partial pressures and temperatures. These factors certainly add to the complexity of interface design, perhaps demanding specific solution to specific CMC system and application. To simplify discussion, potential interface issues will be classified into three temperature regimes; below $800^{\circ} \mathrm{C}, 800^{\circ} \mathrm{C}-1000^{\circ} \mathrm{C}$, and above $1,000^{\circ} \mathrm{C}$.

\subsection{CMCs for Use Below $800^{\circ} \mathrm{C}$}

It is well known that $\mathrm{C}$ coatings will not survive in oxidizing environments at temperatures over $500^{\circ} \mathrm{C}$. However, $\mathrm{BN}$ coatings are oxidatively stable up to $900^{\circ} \mathrm{C}$ and hence should suffice the need for CMCs with use temperatures below $800^{\circ} \mathrm{C}$. The only concern with $\mathrm{BN}$ is its susceptibility to moisture around $600^{\circ} \mathrm{C}$, which is currently being investigated/addessed through the development of highly stoichiometric BN coatings. Reactivity of the coatings under corrosive conditions should not be a major concern at these low temperatures. 


\subsection{CMCs for Use Between $800-1000^{\circ} \mathrm{C}$}

As we go to higher temperatures, concerns mount not only regarding oxidative stability of the coatings, but also due to its reactivity with the corrosive environment. Unfortunately, there is little or no experimental data on the behavior of potential interface coatings in corrosive environments. However, it is well known that even $\mathrm{SiC}$, which forms a protective silica coating, is susceptible under certain application environments [20]. This raises a concern for the fiber (Nicalon) and matrix ( $\mathrm{SiC})$ constituents themselves such that behavior of coatings may not be the major issue. However, these reactions are kinetically active only above $1000^{\circ} \mathrm{C}$, such that $\mathrm{CMCs}$ in this temperature range ought to be viable for use in most DOE applications.

As discussed earlier, recent findings reported by Brennan show that dual coatings consisting of $\mathrm{BN} / \mathrm{SiC}$ on Nicalon fibers function very well under relatively high loads at $1100^{\circ} \mathrm{C}$ [2]. Nicalon reinforced glass ceramic (barium aluminosilicate or $\mathrm{BAS}$ ) matrix composites with $\mathrm{BN} / \mathrm{SiC}$ coatings were fabricated and tested under varying conditions of temperatures and loads. These composites survived even after exposure for 500 hours at $1100^{\circ} \mathrm{C}$ under relatively high loads. It is speculated that the glass matrix allows for crack healing to seal the matrix which protects the coating from the atmosphere. In this dual coating design, the $\mathrm{SiC}$ layer protects the underlying turbostratic BN from coarsening due to the diffusion of matrix elements into the coating which may eventually result in degradation of the fiber properties.

Besides these dual coatings, most of the other published work has been somewhat exploratory in nature. Tin dioxide, due to its poor wetting characteristics with both $\mathrm{SiC}$ and alumina is a potential interface coating material for this temperature range [21]. It does, however, decompose at temperatures above $1100^{\circ} \mathrm{C}$ with the formation of $\mathrm{SnO}(\mathrm{g})$. It is acidic in nature and hence should behave fairly well in acidic environments (silica rich).

As discussed earlier, there is a significant amount of work underway in the development of porous interface coatings. One of the drawbacks of this approach is the sinterability of the pore structure during prolonged exposure to elevated temperatures. However, most ceramics sinter at 
temperatures much above $1000^{\circ} \mathrm{C}$ and hence porous coatings may also serve well for CMCs in this range. On the other hand, with a greater than $30 \%$ level of porosity desired in the coatings to impart low toughness, it will probably have open channels such that corrosive species may have direct access to the fiber and hence there is a risk for composite failure during use. Furthermore, the feasibility of developing porous coatings in a uniform and continuous manner on fiber tows/ fabrics still remains to be evaluated.

\section{$4.3 \mathrm{CMCs}$ above $1000^{\circ} \mathrm{C}$}

Currently, most of the ongoing interface development work in the CMC community is tailored to serve this regime. While many DOE applications set an upper temperature limit of $1250^{\circ} \mathrm{C}$, the DoD needs extend up to $1500^{\circ} \mathrm{C}$. Advanced heat exchangers for DOE are designed for use above $1300^{\circ} \mathrm{C}$, where Nicalon ${ }^{\mathrm{TM}}$ fibers clearly will not be stable. Also, several studies have shown the susceptibility of $\mathrm{SiC}$ to corrosive atmospheres under these conditions. While oxides are obvious candidates as oxidation-resistant interface coatings, their use may not suitable for SiC-based composites. This is primarily due to the potential for oxygen diffusing through and attacking the $\mathrm{SiC}$ fiber and subsequently degrading its strength. Hellman and Coworkers developed a porous $\mathrm{Si}-\mathrm{O}-\mathrm{C}$ coating which may be suitable for $\mathrm{SiC}$-based composites, but the results are somewhat perliminary with further work underway [15]. Also, on-going work at Oak Ridge National Labs in the development of mullite [8] and porous SiC [16] coatings look promising at the present time.

As the problems are foreseen with the corrosion of $\mathrm{SiC}$ at elevated temperatures, some attention is being given to the development of oxide-oxide CMCs with Nextel 610 (alumina) or 720 (mullite and alumina) as fiber reinforcements. As discussed in the introductory section, monazite is the only promising interface coating material to serve the high temperature regimes. It is also compatible with both alumina and mullite and should serve very well in corrosive atmospheres. As mentioned earlier, under a DARPA program, 3M along with SRI and Rockwell is evaluating monazite coatings through the development of mullite-mullite composites. Development of refractory layered oxides, fugitive, and porous coatings are some of the other approaches under study. 


\subsection{INTERFACE WORKING GROUP}

In order to address the difficult issues concerning interface concepts, coating materials, deposition techniques, and interface testing, the Air Force, NASA and Oak Ridge National Laboratory (ORNL) have established an interface working group that will meet once a year to discuss and share the results through an informal setting (Committee Members: Dr. Ronald J. Kerans (WPAFB), Dr.Randall S. Hay (WPAFB), Mr. David Stinton (ORNL), and Mr. Rick Lowden (ORNL), J. Ethridge (NASA), M. Farmer (NASA). This ought to provide useful information for researchers in this field and certainly help in avoiding repetitive work especially with the shrinking budget situation at all ends.

A two-day meeting of the Interface Working Group (6/19-6/20/96) was recently hosted by ORNL at Knoxville, TN where researchers active in the field presented their work. The meeting was well attended and the exchange of infomration was fruitful resulting in several collaborative projects. During the meeting, it was proposed that a web site be created to post relevant information and to address critical processing issues.

\subsection{COATING DEPOSITION}

An ongoing debate in the CMC community is whether solution- or CVD-based coating approaches are suitable for developing continuous fiber coatings. The key objective is to coat fiber tows uniformly across the filaments in a tow and over long lengths without degrading the fiber strengths by more than $10 \%$. Precursors for solution-based techniques include particulate sols, polymeric sols, slurry suspension, and inorganic salt mixtures dissolved in aqueous media. Concentrated solutions are used in order to make the process efficient such that few passes are sufficient to get the desired thickness on each filament (typically $40-80 \mathrm{~g} / \mathrm{L}$ ). While the development of continuous-fiber coating for solution-based techniques is relatively new, coating fibers continuously by CVD has been performed for over a decade, and some coatings can be obtained commercially from several sources. Almost all the $\mathrm{C}$ and $\mathrm{BN}$ coatings designed for CMCs are deposited by CVD. While there are pros and cons for both solution and CVD 
approaches, it depends largely on the nature of the coating material and the concept being proposed. Some of the relevant issues are discussed below:

\section{$\underline{6.1}$ Cost}

In general, it is believed that the CMC cost will eventually be driven by the cost of the fiber and interface coatings. Without getting into a detailed economic analysis, it is reasonable to expect solution-based coating approaches to be far less expensive than CVD. This is based upon the significantly lower capital, operating, and precursor costs associated with solution-based processes.

\subsection{Coating Uniformity and Reliability}

It is widely believed that CVD currently offers better coating uniformity, particularly on woven or braided preforms, is not easily feasible with solution based techniques. Hay and coworkers, at Wright Laboratory, have been working extensively on developing fiber coatings of various metal oxides by solution techniques in a continuous manner [22]. Their technique involves passing the fiber tows through an aqueous coating solution first and then through an immiscible liquid layer( usually 1-octanol or hexane) which prevents fibers from bridging with one another. Certainly, their efforts over the past five years has resulted in attaining better control of the process, but it still lacks the reproducibility offered by CVD. The quality of coatings obtained by solution methods is dictated by the local chemistry at the fiber-coating interface, where subtle changes in the solution chemistry can introduce variation in composition, thickness and morphology. However, Hay's recent work on monazite coatings deposited on Nextel 720 fibers shows encouraging results [23]. Goettler has also developed a similar process with excellent fiber strength retention properties [24]. Weibull plots obtained from coated tows that were annealed at $1100^{\circ} \mathrm{C}$ for $1 \mathrm{hr}$ show virtually no strength degradation compared to the strength of uncoated tows annealed under similar conditions. These results present an optimistic outlook for solution based approaches. 


\section{$\underline{6.3 \text { Substrates }}$}

Interface coatings can be either deposited on fiber tows with subsequent weaving and braiding of the coated tows or directly on to woven fabrics/preforms. While it is desirable to do the latter, it is obviously not an easy task. CVI processes are certainly feasible for directly coating fabrics/ preforms whereas a solution-based approach may suffer from nonuniform wetting and and fiber bridging. On the other hand, while CVI coatings with relatively simple chemistries such as $\mathrm{C}$ or $\mathrm{BN}$ or $\mathrm{SiC}$ have been demonstrated, developing CVI processes to deposit multicomponent oxides uniformly may be quite a difficult task. For fiber tow coatings, several concerns arise regarding the handlability of the coated fibers during weaving. Spallation of the coating during the weaving process is certainly worrisome.

\section{$\underline{6.4 \text { Coating Materials }}$}

At the present time, there is little debate that CVD is the preferred technique for depositing nonoxide coatings on fibers. However, the situation is quite different with depositing complex oxides. In CVD processes, the precursor chemistry has to be tailored such that decomposition of the various metal precursor components occur synchronously such that the desired composition (metal ratio) is obtained throughout the length of the hot zone. For most oxides, metal-organic based precursors are used which are fairly expensive. These precursors also contain significant fraction of hydrocarbons such that it is difficult to avoid incorporation of carbon in the deposit unless high temperatures are used (above $800^{\circ} \mathrm{C}$ ). Higher deposition temperatures are also required to promote dense, uniform, and, as required in some cases, oriented coatings. The use of high temperatures, however, is not suitable for obtaining uniform infiltration. in that outer filaments tend to have thicker coatings while the inner fibers are either not coated at all or have very thin coatings.

\subsection{INTERFACE TESTING}

A truly frustrating aspect of this research is the lack of a comprehensive test method for determining interface properties. Often times, it is expected that crack deflection observed in monofilament-based composites is "proof enough" such that the concept is transferable to real 
composite systems which is often found to be not true or difficult to prove due to processing limitations. There are basically two philosophies that guide the various approaches toward demonstrating the concept. One, which is "basic science" oriented, is to develop coatings on monofilaments and process them into composites through hot pressing and test the interface for crack deflection. If the results look promising, proceed toward preparing tow composite specimens for tensile testing. Yet another approach is to coat fabrics and process 2D composites for testing and subsequently determine interface properties from pull-out behavior. Interface properties are assessed based on fiber pull-out behavior through the examination of fracture surfaces. This is certainly a safe approach toward developing a complete workable CMC system.

\subsection{FIBER STRENGTH DEGRADATION}

Fiber strength is known to degrade significantly during the coating process and the extent of degradation depends on the nature of the fiber, coating material, and the coating method employed. Strength degradation has been observed for both CVD- and solution-coated fibers. Hay and coworkers [25] at Wright labs are conducting an extensive effort in understanding fiber strength degradation for $3 \mathrm{M}$ 's Nextel 720 by testing under various conditions and then correlating the flaw generation with TEM characterization. It appears that merely passing the Nextel 720 fiber through solutions of water and dilute nitric acid can cause some degradation in fiber strength. The cause is not well understood. Babcock \& Wilcox develops their fiber coating process based first on strength degradation. Once the process is optimized, such that strength degradation is minimum, composite specimens are made and the interface properties are subsequently tested through tensile tests. Goetller, at Babcock and Wilcox, has computed weibull plot comparisons between monazite-coated Nextel 720 fibers obtained from various sources and uncoated fibers annealed under similar conditions. The plots show very little degradation for the B\&W monazite sols whereas significant degradation is observed for fibers coated with the sol obtained from BIRL. It is believed that slight deviations in lanthanum to phosphorous stoichiometry in the BIRL sol is responsible for the severe strength degradation. A slight excess of lanthanum in the sol may react with alumina grains in the fiber causing the strength to go down. While a phosphorous excess in the sol results in the formation of aluminum phosphate at the fibercoating interface which also deteriorates the fiber properties. Therefore, precise stiochiometry is 
crucial in developing coatings that do not affect fiber properties. Monazite being the first generation of oxide interface coatings where such extensive characterization of the interface has allowed us to understand and appreciate subtle effects of chemistry.

\subsection{AREAS FOR FUTURE DEVELOPMENT}

Since the discovery of carbon and $\mathrm{BN}$ coatings, many CMC programs have been initiated through funding from federal agencies across most disciplines with the Air Force and DOE staking the primary interest. Most programs have addressed basic research issues in the development of oxidatively stable interface coatings for high temperature applications (above $1200^{\circ} \mathrm{C}$ ). Industrial participation has also been fairly strong with Rockwell Intl. leading the way in the development of monazite coatings for mullite- and alumina-based CMC systems. Despite these efforts, the problem remains largely unresolved and much of this actually reflects the complexity of the problem. As discussed earlier, the difficulty lies in demonstration of a proposed concept. Often, limitations in processing of the fiber coatings to obtain the appropriate chemistry, morphology, and uniformity has hindered the progress. Furthermore, extending the proof of concept from model composites (monofilament-based) to a practical composite system (test panels made using fiber tows/fabrics) has not materialized in most cases.

In addition, most programs have lacked an emphasis on characterization of fiber coatings. Characterization of fiber coatings is critically important to understand the coating's related mechanical response of debonding and sliding and the influence of coating on the fiber strength. Chemical interdiffusion occuring between the coating and fiber materials at elevated temperatures can be detrimental to interface properties and fiber strength as demonstrated in many studies. In light of the above discussion, we recommend that DOE sponsor CMC programs which gives equal weight to concept demonstration, coating characterization, and interface testing such that a cumilative understanding is gained. Some efforts should be employed to develop standard screening tests for determining interface properties. It is only recently that the use of microcomposites for testing interface properties is gaining worldwide recognition. This is an area that certainly warrants further development. Methods for fabricating both tow- and monofilament-based microcomposites with reproducible properties should be developed. 
For many of the DOE applications, such as hot gas filters, the corrosive nature of the environment also raises concern about the stability of the coating and other constituents of the CMC system (fiber, coating, and matrix). While previous studies suggest that the chemistry of the fiber-matrix interface should be carefully controlled to avoid adverse effects on the fiber and interface properties, the coal-fired environment may also disrupt the chemical balance and initiate deleterious reactions at the interface. Corrosive species from the environment can diffuse through the porous matrix or through cracks prevalent in the matrix and attack the coating. While the coating may be inert toward certain species of the environment, they may react aggressively with others as the coal-based environment encompasses a wide range of chemistries. Therefore, future programs should emphasize the need to tailor the chemistry of the coating such that the application environment is also included as part of the selection criteria requirements.

In summary, the recommendations for future development for CMCs are in the following areas:

- Coordinate with DoD to sponsor programs for the development of oxide-oxide CMCs

- Invest to accelerate the development of microcomposites for screening interface coatings

- Encourage development of new and creative concepts that are high risk, but may result in critical breakthroughs

- For SiC-based systems, new approaches to interface design should be given priority

- Programs should include corrosion tests for screening interface coatings 


\subsection{REFERENCES}

1. M. Y. He and J. W. Hutchinson, "Crack Deflection at the Interface between Dissimilar Materials," Int. J. Solids Struct., 25, 1053-67 (1989).

2. J. J. Brennan, S. R. Nutt, and E. Y. Sun, "Interfacial Microstructure and Stability of BNcoated Nicalon Fiber/Glass-Ceramic Matrix composites", High-Temperature Ceramic Matrix Composites II, Ceramic Transactions, 58 (1995) 53-64.

3. L. Snead, "Development of Silicon Carbide Composites for Fusion." Fusion Technology, 24, 65-82 (1993).

4. R. S. Hay. E. Boayke, and D. Petry, "Continuous Sol and Solution derived Monazite Coatings on Ceramic Fiber Tows", presented at the Annual Meeting of the American Ceramic Society, Indianapolis, IN, April 1996.

5. A. G. Evans and R. Naslain, "High Temperature Ceramic Composites", Proceedings of the Second International Conference on High-Temperature Ceramic-Matrix Composites, held August 21-24, 1995, Santa Barbara, CA, Ceramics Transactions, Vol. 58, published by American Ceramic Society, 1995.

6. P. E. D. Morgan and D. B. Marshall, "Ceramic Composites of Monazite and Alumina", J. Am. Ceram. Soc., 6 (1995) 1553

7. R. J. Kerans, "The Role of Coating Compliance and Fiber/Matrix Interfacial Topography on Debonding in Ceramic Composites," Scr. Metall. Mater., 32 [4] 505-509 (1995).

8. D. P. Stinton, R. A. Lowden, E. R. Kupp, and O. J. Schwarz, “Development of Oxidation Resistant Interface Coatings", presented at the Annual Meeting of the American Ceramic Society, Indianapolis, IN, April 1996.

9. R. F. Cooper and P. C. Hall, "Reactions between Synthetic Mica and Simple Oxide Compounds with Application to Oxidation-Resistant Ceramic Composites," J. Am. Ceram. Soc., 76 [5] 1265-73 (1993).

10. P. E. D. Morgan and D. B. Marshall, "Functional Interfaces for Oxide/Oxide Composites," Mater. Sci. Eng., A, 162, 15-25 (1993).

11. P. W. Brown and S. Sambasivan, "MOCVD of Beta Alumina", in 18th Annual Conference on Composites and Advanced Ceramic Materials, Coca Beach, FL, 1994.

12. M. Cinibulk and R. S. Hay, "Textured Magnetoplumbite Fiber-Matrix Interphase Derived from Sol-Gel Fiber Coatings", J. Am. ceram. Soc. 79 [5] 1233-46 (1996).

13. S. Sambasivan and W. T. Petuskey, "Oxidation Resistant Interface Materials for High Temperature Ceramic Matrix Composites", presented at the Annual Meeting of the American Ceramic Society, Indianapolis, IN, April 1996.

14. M. H. Jaskowiak, S. I. Eldridge, J. B. Hurst, and J. A. Setlock, "Interfacial Coatings for Sapphire/ $\mathrm{Al}_{2} \mathrm{O}_{3}$ ", p. 84 in HITEMP Review, NASA Conference Publication No.10082, 1991. 
15. J. R. Hellman and M. Stough, "Development of porous Si-O-C coatings", presented at the Annual Meeting of the American Ceramic Society, Indianapolis, IN, April 1996.

16. L. Kupp "Development of porous SiC coatings" presented at the second conference of the Interface Working Group meeting, Knoxville, TN, June 19-20 1996.

17. T. Mah, K. A. Keller, T. A. Parthasarathy, and J. Guth, "Fugitive Interface Coating in Oxide-Oxide Composites," Ceram. Eng. Sci. Proc., 12 [9-10] 1802-15 (1991).

18. Proceedings of the Advanced Coal-Fired Power Systems Review Meeting, July 16-18, 1996, DOE-METC

19. R. Naslain, "The Concept of Layered Interrphases in SiC/SiC", High-Temperature Ceramic Matrix Composites II, Ceramic Transactions, 58 (1995) 23-40.

20. N. S. Jacobson, "Corrosion of Silicon-Based Ceramics in Combustion Environments," J. Am Ceram. Soc. 76 [1], 3-28 (1993).

21. K. K. Chawla, M.K. Ferber, R.Venkatesh, Z.R.Xu, Mater. Sci. \& Eng., v162, p35 (1993).

22. R. S. Hay, M. D. Petry, K. A. Keller, M. K. Cinibulk, and J. R. Welch, "Carbon and Oxide Coatings on Continuous Ceramic Fibers," Mater. Res. Soc. Symp. Proc., 365, 1995.

23. E. Boayke, D. Petry, and R. S. Hay, "Sol and Solution Derived Monazite", presented at the Annual Meeting of the American Ceramic Society, Indianapolis, IN, April 1996.

24. R. Goettler and S. Sambasivan, “Monazite Fiber Coatings", presented at the Annual Meeting of the American Ceramic Society, Indianapolis, IN, April 1996.

25. R. S. Hay, unpublished results. 
M97002188

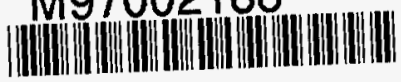

Report Number (14) DDE /MC/32085- 5522

subl. Date (11) 19970109

sponsor code (18) DOE $F E, X F$

JC Category (19) UC-1OI, DOE/ER

DOE 


\title{
A software system for the analysis of the "giornate" sequences in frescoes
}

\author{
poster presented at the day conference on \\ "The analysis of pigments and plasters" \\ British Museum, London 22-2-1997
}

organized by the Wall Paintings Section of the United

Kingdom Institute for Conservation

\section{Bertorello^, L. Bordoni^^, A. Colagrossi*, G. Martellotti^, C. Seccaroni**}

${ }^{\wedge}$ C.B.C. - Conservazione Beni Culturali Roma

*IASI-CNR Roma

$\wedge \wedge$ ENEA/STUDI/Doe - C.R. Casaccia Roma

**ENEA/INN/Art-C.R. Casaccia Roma 


\begin{abstract}
This paper reports on a software system for the analysis of the giornate sequences in frescoes, based on mathematical modelling. This model takes into account whole giornate and the relations defined on them by the temporal precedence in their realisation. A sample application is provided on frescoes by Luca Signorelli in the Cappella di San Brizio in the Orvieto Cathedral.
\end{abstract}

[Computer software, computer art, fresco, plasters, wall painting, Signorelli]

\title{
RIASSUNTO
}

Viene presentato lo sviluppo di un sistema software per l'analisi della sequenza di esecuzione delle giornate di un affresco. Tale sistema si basa su una modellizzazione matematica che considera da un lato l'insieme delle giornate e dall'altro la particolare relazione tra di esse, definita dalla precedenza temporale nella realizzazione. Viene inoltre fornita un'applicazione del sistema su affreschi eseguiti da Luca Signorelli nella Cappella di San Brizio nel Duomo di Orvieto. 


\section{PROBLEM DEFINITION}

The technique of the fresco needs the execution of the painting directly on the wet plaster, before the carbonatation on its surface; for this reason the plaster must be drawn up only in the zone to be painted in one day (giornata). The careful examination of the joint between two adjacent giornate allows one to detect the overlapping of the plasters, so it is possible to establish the temporal precedence in the realisation of the interested giornate. The examination of the binary relationships concerning all the couples of adjacent giornate on the whole surface of a fresco permits to focalize the going on of the works during the execution of the painting. In the case of frescoes having a wide extension, the giornate number can be very high, so it is very difficult to consider and to elaborate the whole information concerning the joints.

The software system implemented for the analysis of the giornate in fresco paintings is based on a mathematical modelling that takes into account the whole giornate and the relation defined on them by the temporal precedence in their realisation. The mathematical model that fits this specific situation is the model of the direct acyclic graphs (dag).

\section{CHARACTERISTICS OF THE SYSTEM}

In addiction to the temporal sequence the system allows:

- to point out possible anomalies, due to errors in the detection of the direction of the joints among the giornate, for example by the indication of the presence of loops;

- to simulate and to elaborate the different possible interpretations in the case it is impossible to detect the direction of the joints;

- to improve the readability of the whole giornate sequence by clustering selected subsequences.

The software system processes information concerning the overlapping of the plaster among one giornata and all the other adjacent giornate; it automatically eliminates redundant information by applying the maximal path algorithm; so it is possible to obtain the correct temporal sequence for the execution of the giornate.

The system runs on personal computer under MS-DOS operative system and it does not need any sophisticated configuration. In order to enable the graphic visualisation mode, it is necessary a WINDOWS 3.1 version or greater.

The system makes available to the user a wide number of features, implemented by means of several program modules. The system's features are:

- inserting, updating, deleting and accessing data concerning the plasters overlapping for the whole giornate in the fresco;

- detecting possible loops in the graph corresponding to the inserted data;

- processing the graph corresponding to the inserted data yielding an acyclic graph with no redundant information;

- visualising the resulting graph;

- constructing clustered graphs. 
The data input occurs after a preliminary numbering of all the giornate of the fresco. At this point all that is needed is to enter the couples of numbers corresponding to the adjacent giornate and to the direction of their junction.

The inserted graph elaboration is made by a module that implements the maximal path algorithm. This elaboration must be preceded by the verification of the loops presence in the graph supplied by the user. This test is automatically carried out by the system which, whenever a loop is detected, points out all the nodes interested by the loop.

The result of the execution of the module based on the maximal path algorithm is provided in two distinct modes, depending on the user's choice:

(1) couples of numbers, corresponding to the giornate;

(2) the usual graphical representation: nodes connected by arcs.

Before producing clustered graphs a preliminary selection of the graph nodes to be clustered in only one node must be done.

\section{LOOPS, LACK OF INFORMATION AND CLUSTERING}

A loop occurs when, following the information concerning the joints of two or more giornate, the program comes to a previously examined giornata; this is a collapse situation because the sequence for the ordered giornate assumes a ring structure. The existence of a loop is unacceptable because it is incompatible with the precedence relations inferred by the overlapping of the plasters at the joints. Further, a loop makes the program removing the redundant information non-terminating. In order to avoid such a critical situation, when a loop is detected the program points out this situation and all the giornate interested by the loop. This signal allows the user to visualise the loop on the plotting, so it will possible to verify directly on the fresco surface the overlapping of the interested joints and to change the incorrect information in the input file.

If it is not possible to look over the fresco surface, the loop elimination can be done inverting the direction of one or more joints following opportune considerations. Alternatively, it can be done considering as only one giornata all the giornate that are interested by the loop (in this case the giornate must be adjacent).

The absence of information concerning either the recognition of giornate or the direction of the plaster overlapping in the joints, can substantially modify the final result; the amount of the produced alteration depends on the information lack in the input data.

In the second case, that is when it is impossible to ascertain the precedence between two adjacent giornate, it must be underlined that this circumstance can not be determinant for the reconstruction of the real sequence: in fact the impossibility to establish a precedence relation between two adjacent giornate sometimes can not determine a real loss of information. The system is able to establish if the unregistered information is redundant, i.e. it does not determine any change in the correct ordering, on the other hand it is essential, because its nonregistration causes a different solution by the algorithm.

The reconstruction of only one linear sequence is an extremely rare case; in fact, the increment of the number of the giornate makes the graph very branched.

Especially for frescoes having a wide extension some considerations concerning the organisation of the work allow one to pick up additional information for the general ordering of all the giornate, independently from the study of the joints. For instance it is evident that if it is possible to know the borders due to the level of the scaffold used for the realisation of the 
fresco, like it happens between two adjacent giornate, it is possible establish a precedence relation between all the giornate under the above scaffold level and those under it. This operation allows for clustering the giornate, so that during the execution of the program all those giornate are treated as one only giornata.

\section{A SAMPLE APPLICATION}

This software system has been tested on the frescoes by Beato Angelico and Luca Signorelli in the Cappella di San Brizio in the Orvieto Cathedral; the whole fresco surface consists of more than 900 giornate. In figure 2 is shown the sequence concerning the giornate map for the Hell painted by Luca Signorelli; the same is shown as a graph in figure 3. In figure 4 and in figure 5 the situation concerning the Heaven, in the same Chapel, is shown. In both the maps the supposed levels for the scaffold are shown, they are different for number and tallness in this two scenes; finally in the graphs the giornate concerning local correction are shown with round areas.

The comparison of the situation for these two scenes clearly shows that for the Heaven the works have been processed in a more articulate way. For the Hell, on the contrary, with the exclusion of the branches due to the giornate concerning local corrections, four long linear sequences have been evidenced. Stylistic and technical considerations allow one to make the hypothesis that the Hell was the first scene frescoed by the painter on the walls of the Chapel, so it is interesting to have verified that this scene is different from the other also for the giornate organisation. The less branched structure of the Hell could be due to the absence of assistants in the first phase of the works; this circumstance allows to the painter to directly evaluate the problems due to the planning and the realisation of so large scenes. During the recent restore of the whole frescoes in the Chapel it has been verified in the Hell a greater number of corrections and a secco finishings; these corrections also concern the architectural structure of the scene.

\section{BIBLIOGRAPHY}

M. Bottoni, M. Cordaro, M.C. Gaetani, B. Provinciali: Sviluppo di un sistema sperimentale per l'analisi dinamica delle fasi di esecuzione di affreschi. Finalità e fasi del progetto. $2^{\mathrm{a}}$ Conferenza Internazionale sulle prove non distruttive, metodi microanalitici e indagini ambientali per lo studio e la conservazione delle opere d'arte, Perugia 17-20 aprile 1988, vol. I 13.1-15.

G. Ausiello, A. Marchetti Spaccamela, M. Protasi: Teoria e progetto di algoritmi fondamentali, Franco Angeli, Milano, 1988.

C. Batini, L. Carlucci Aiello, M. Lenzerini, A. Marchetti Spaccamela, A. Miola: Fondamenti di programmazione dei calcolatori elettronici, Franco Angeli, Milano, 1992. 
Fig. 1 - Luca Signorelli: the Hell. Particular with the overlapping of the plasters at the joint among the giornate.

Fig. 2 - Luca Signorelli: the Hell. Map of the giornate with the paths of the execution sequence.

Fig. 3 - Luca Signorelli: the Hell. Sequence of the giornate.

Fig. 4 - Luca Signorelli: the Heaven. Map of the giornate with the paths of the execution sequence.

Fig. 5 - Luca Signorelli: the Heaven. Sequence of the giornate. 


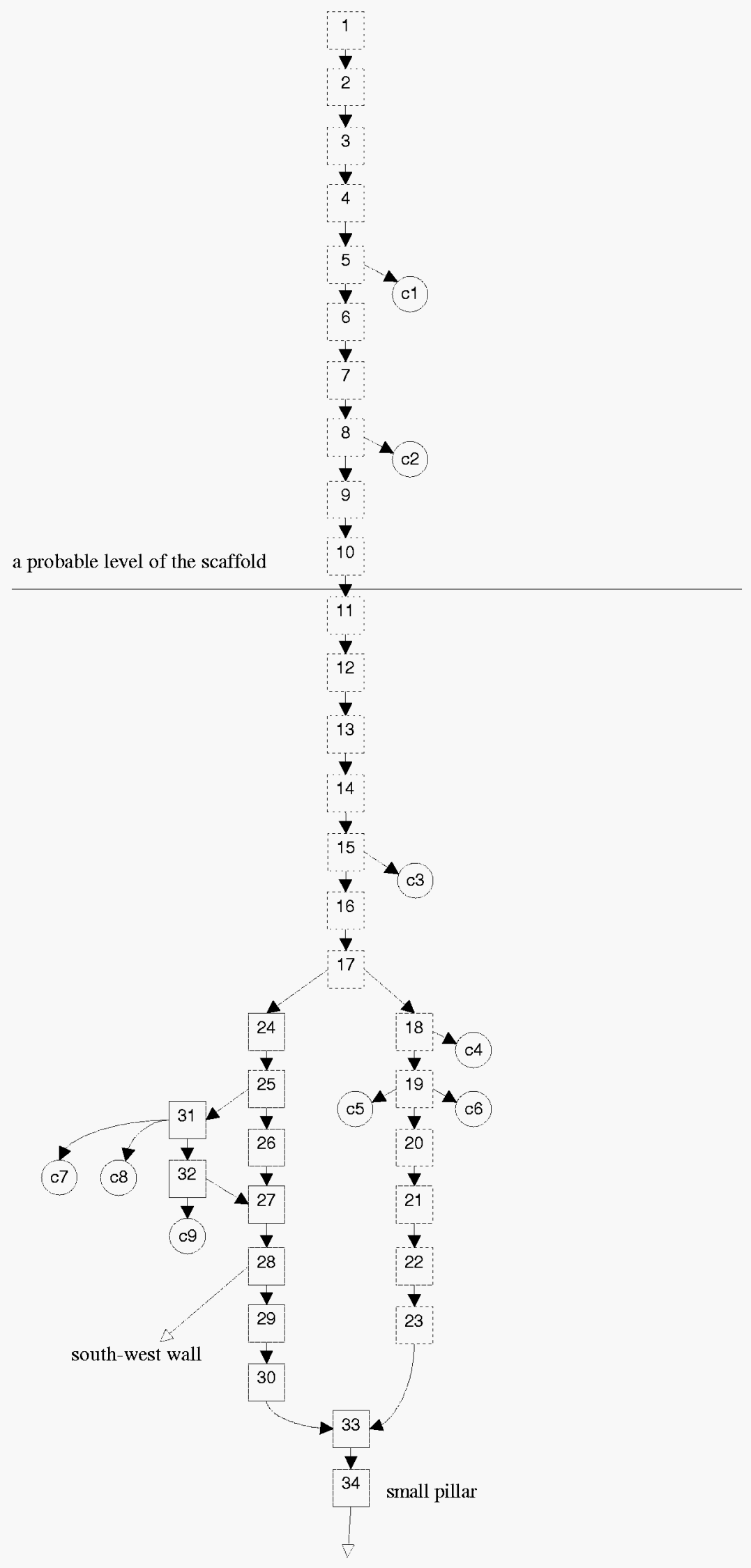

The Resurrection of the body

Figure 3 


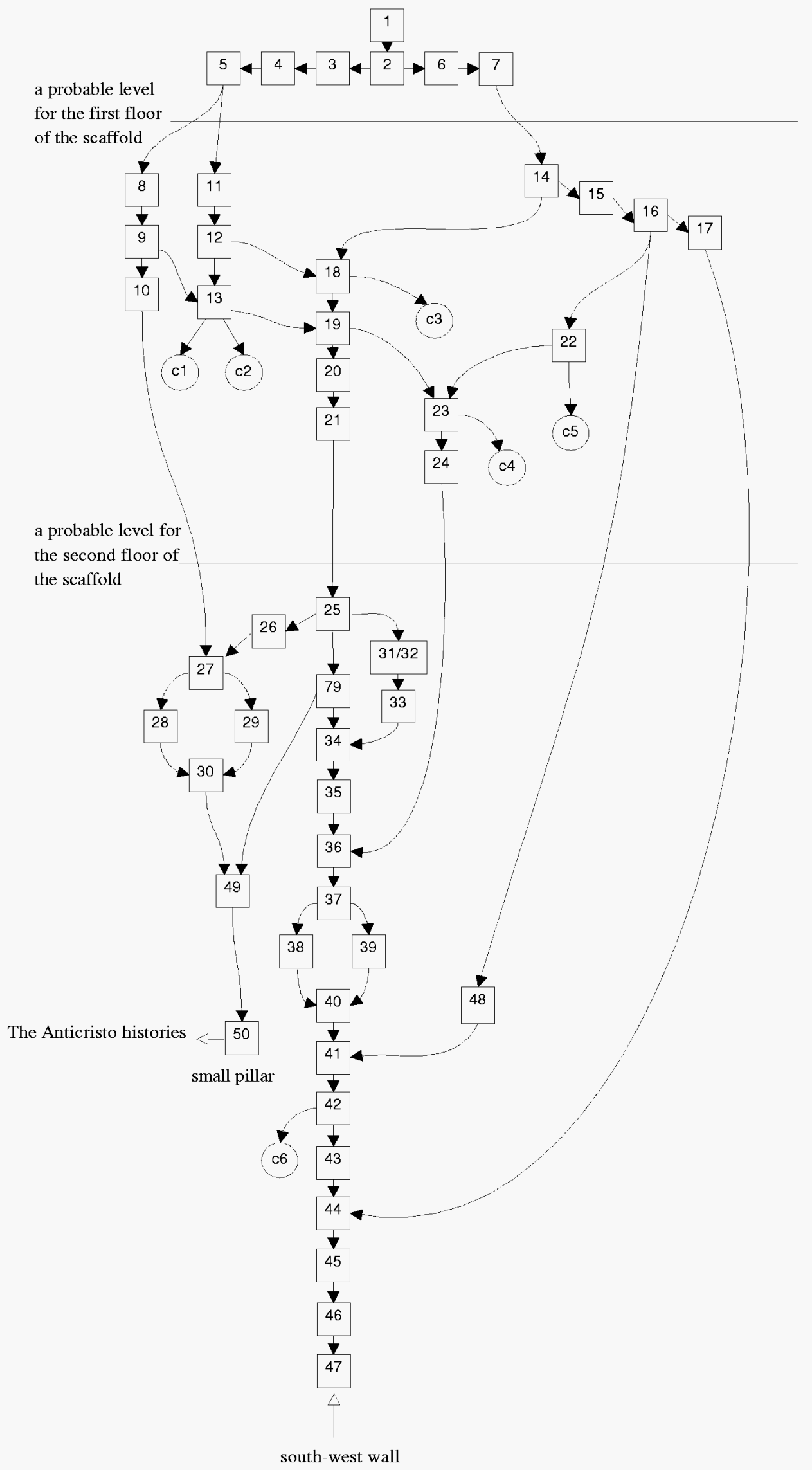

Figure 5 
